\title{
Seasonal variability of the composition and structure of parasite communities of red porgy, Pagrus pagrus (Perciformes: Sparidae) off Brazil
}

\author{
I. A. SOARES' ${ }^{1}$, J. L. LUQUE2*
}

${ }^{1}$ Curso de Pós-Graduação em Ciências Veterinárias, Universidade Federal Rural do Rio de Janeiro, Seropédica, Rio de Janeiro, Brazil; ' $D$ Departamento de Parasitologia Animal, Universidade Federal Rural do Rio de Janeiro, Seropédica, Rio de Janeiro, Brazil, E-mail: luqueufrr@gmail.com

\section{Article info}

Received November 22, 2014 Accepted February 17, 2015

\begin{abstract}
Summary
A study of seasonal variation of metazoan parasite community of Pagrus pagrus was conducted between January and December 2012. Two hundred forty specimens of Pagrus pagrus were collected in four seasons (autumn and winter in dry season and spring and summer in rainy season) from off the state of Rio de Janeiro, Brazil. Twenty one species of metazoan parasites were found, with larvae of Hysterothylacium sp. being the dominant species. The highest values of prevalence and abundance was during the rainy season with peak prevalence of monogeneans and nematodes, period of action of the South Atlantic Central Waters (SACW) and reproductive activity of the host, suggesting that the sasonal variation in the parasites community was influenced for these phenomena.
\end{abstract}

Keywords: Pagrus pagrus; seasonal variation; metazoan parasites

\section{Introduction}

Parasitism plays an important role in biology of fish because parasites influence host survival and reproduction; they can also alter fish behaviour and migration patterns, and can even regulate fish populations and affect fish community structure (Gordon \& Rau, 1982; Poulin \& Fitzgerald, 1987; Garnick \& Margolis, 1990; Barber \& Poulin, 2002).

A large number of studies have focused on the structure of communities of parasites of marine fish. However, many of them did not consider spatial and temporal variations in community structure, and thus the detection of relevant local or short-term processes (Poulin \& Valtonen, 2002). Studies related with the population and community ecology of fish parasites are carry out in order to determine their natural modifications, including both biotic and abiotic factors of the host-parasite system that affect its dynamics (Díaz \& George-Nascimento, 2002).

Processes such as variations in temperature and other abiotic factors, the abundance of intermediate hosts, changes in abundance, reproductive behaviour and diet of definitive hosts and factors related to host immunity have been suggested to influence the seasonal variation in communities of parasites of marine fish in tropical regions (Carvalho \& Luque, 2011; Soares et al., 2014).
Thus, seasonal studies are necessary to elucidate additional aspects of the structures of the parasite community in $P$. pagrus.

Pagrus pagrus popularly known as red porgy is a demersal fish, which feeds on a wide variety of benthic and demersal fish, and invertebrates. It is a fish of significant commercial value (Ávila \& Haimovici, 2004) and is widely distributed in the Eastern Atlantic since the British Isles south to coastal zone of Angola, also occurring in the Mediterranean and the Adriatic Sea. In the Western Atlantic is distributed from the coast of New York, USA to southern Argentina (Manooch \& Hassler, 1978; Menezes \& Figueiredo, 1980). The main objective of this work was to detect possible patterns of seasonal variability in the composition and structure of parasite communities of Pagrus pagrus, in the coast of Rio de Janeiro, RJ, Brazil.

\section{Material and Methods}

We examined 240 specimens of Pagrus pagrus collected from the coast of Municipality of Cabo Frio, State of Rio de Janeiro (22 $52^{\prime} 43$ "S, 42 ${ }^{\circ}$ '12" W), Brazil between January and December 2012. The sample fish were divided into 4 groups of 60 individuals for every season, i.e. autumn and winter (dry season) and spring and summer (rainy season). Host specimens were identified according to 
Table 1. Prevalence, range of variation of intensity, mean intensity, mean abundance and site of infection of metazoan parasites of Pagrus pagrus $(\mathrm{n}=240)$ from the coastal zone of the state of Rio de Janeiro, Brazil

\begin{tabular}{|c|c|c|c|c|c|}
\hline Parasite & $\begin{array}{c}\text { Prevalence } \\
(\%)\end{array}$ & Intensity & $\begin{array}{c}\text { Mean } \\
\text { Intensity }\end{array}$ & $\begin{array}{c}\text { Mean } \\
\text { Abundance }\end{array}$ & Site of infection \\
\hline \multicolumn{6}{|l|}{ DIGENEA } \\
\hline Lecithochirium sp. & 5 & $1-11$ & 2 & $0.13 \pm 0.83$ & Stomach \\
\hline Parahemiurus merus & 8 & $1-12$ & 3 & $0.23 \pm 1.30$ & Intestine \\
\hline \multicolumn{6}{|l|}{ MONOGENEA } \\
\hline Anoplodiscus longivaginatus & 15 & $1-6$ & 2 & $0.27 \pm 0.80$ & Gills \\
\hline Echinopelma brasiliensis & 25 & $1-4$ & 1 & $0.33 \pm 0.66$ & Gills \\
\hline Encotyllabe spari & 65 & $1-41$ & 7 & $4.68 \pm 6.71$ & Pharyngeal plates \\
\hline Lamellodiscus baeri & 13 & $1-30$ & 4 & $0.45 \pm 2.27$ & Gills \\
\hline Polyabroides multispinosus & 5 & $1-3$ & 1 & $0.06 \pm 0.29$ & Gills \\
\hline Pseudempleurosoma sp. & 0.2 & $1-2$ & 1 & $0.05 \pm 0.31$ & Esophagus \\
\hline \multicolumn{6}{|l|}{ ACANTHOCEPHALA } \\
\hline Corynosoma australe & 2.5 & $1-9$ & 5 & $0.11 \pm 0.84$ & Mesenteries \\
\hline \multicolumn{6}{|l|}{ NEMATODA } \\
\hline Anisakis sp. (larval) & 23 & $1-65$ & 10 & $2.38 \pm 7.37$ & Mesenteries and liver \\
\hline Contracaecum sp.(larval) & 4 & $1-9$ & 3 & $0.12 \pm 0.74$ & Mesenteries and liver \\
\hline Hysterothylacium sp. (larval) & 92 & $1-156$ & 25 & $22.9 \pm 26.1$ & Mesenteries and liver \\
\hline Raphidascaris sp.(larval) & 13 & $1-59$ & 10 & $1.28 \pm 5.59$ & Mesenteries and liver \\
\hline Terranova sp.(larval) & 3 & $1-9$ & 4 & $0.13 \pm 0.84$ & Mesenteries and liver \\
\hline Cucullanus sp. & 2 & $1-2$ & 2 & $0.03 \pm 0.20$ & Intestine \\
\hline \multicolumn{6}{|l|}{ COPEPODA } \\
\hline Clavellotis pagri & 32 & $1-10$ & 2 & $0.74 \pm 1.55$ & Gill rakers \\
\hline Ergasilus sp. & 0.3 & 1 & 1 & $0.03 \pm 0.17$ & Gills \\
\hline Lernanthropus caudatus & 9 & $1-4$ & 2 & $0.16 \pm 0.61$ & Gills \\
\hline \multicolumn{6}{|l|}{ ISOPODA } \\
\hline Cymothoid larval & 25 & $1-672$ & 48 & $12.3 \pm 56.7$ & Gills \\
\hline Cymothoidae gen. $\mathrm{n}$. & 0.3 & 1 & 1 & $0.03 \pm 0.18$ & Gills \\
\hline
\end{tabular}

Menezes and Figueiredo (1980); their total body length was 18-42 $\mathrm{cm}$ (mean $32.2 \pm 5 \mathrm{~cm}$ ). The collection and processing of the parasites was made according to Eiras et al. (2006). The identification of the parasites follows Tavares and Luque (2006) for anisakid larvae, Cohen et al. (2013) for Monogenea, Kohn et al. (2007) for Digenea, and Santos et al. (2008) for Acanthocephala and Luque et al. (2013). The statistics analysis included only parasite species with prevalence higher than $10 \%$ (Bush et al., 1990). In all comparisons, data were considered significantly different when a bilateral obtained probability $p<0.05$. Analysis of variance (ANOVA) of transformed data with $\log (x+1)$ was used to compare parasite abundance. Chi-square test analyzes were used to test for significant differences in the prevalence values (Zar, 1996).Non-metric multidimensional scaling (NMDS) based on the Bray-Curtis simi- larity index was used to obtain an ordination of the infracommunity metazoan parasites according to their relative similarities in parasite abundances. This analysis was performed using 100 random departures with two and three-dimensional configurations in order to find the optimum ranking. All the methods yielded similar results, but three-dimensional ranking based on the $\log (x+1)$ transformation was ultimately chosen because it provided the best quality ranking (assessed using the stress value and inspection of Sheppard plots). One-way analysis of similarity (ANOSIM) was used to determine the significance of possible grouping patterns in the NMDS ranking (Clarke, 1993).The differences in infracommunity composition were tested through one-way permutational multivariate analysis of variance (PERMANOVA) a permutation of residuals with a reduced model was used as method of permutation. 


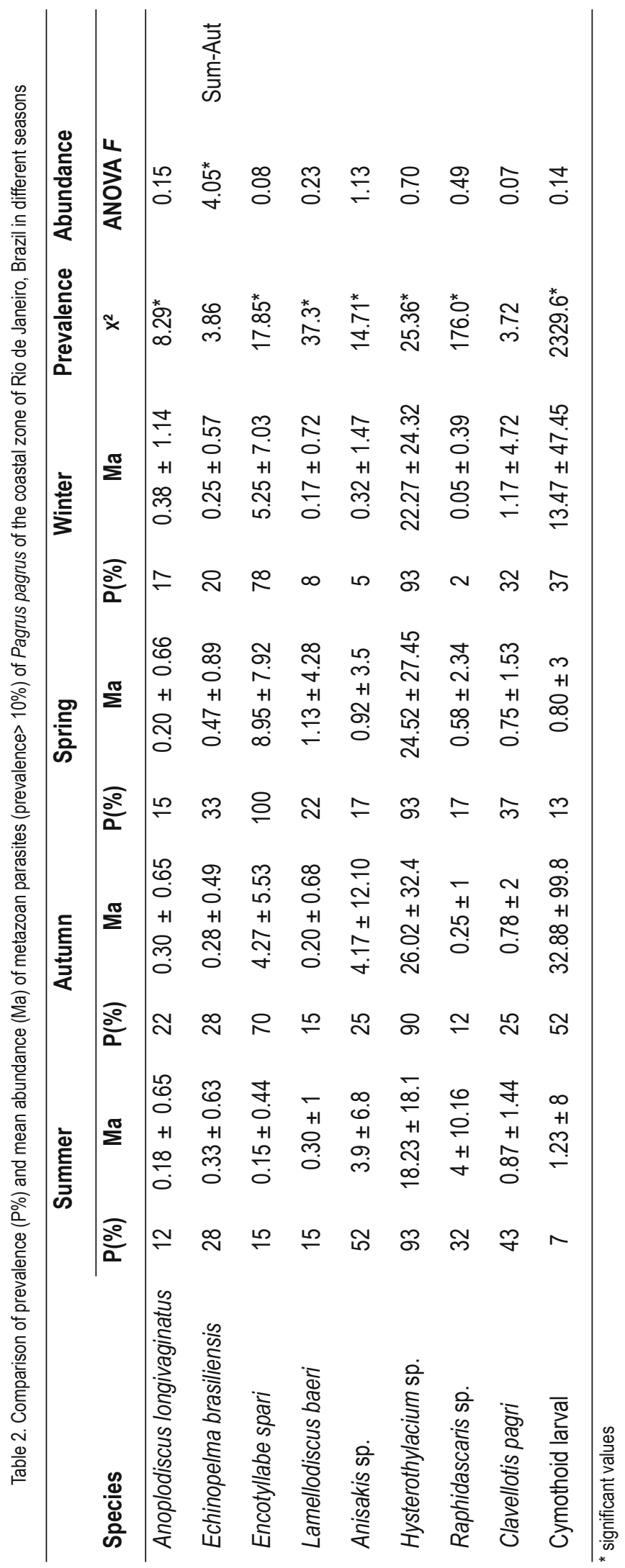


Table 3. Quantitative features in the infracommunity metazoan parasites of Pagrus pagrus coastal area of the state of Rio de Janeiro. Brazil. F = values from ANOVA for comparison between the hosts

\begin{tabular}{lccccc}
\hline Features /species & Summer & Autumn & Winter & Spring & ANOVA $\boldsymbol{F}$ \\
\hline Richness of species & 19 & 19 & 18 & 18 \\
Total number of specimens & 1.839 & 4.188 & 2.664 & 2.395 \\
Average parasite richness & $3.4 \pm 1.4$ & $3.7 \pm 1.6$ & $3.2 \pm 1.4$ & $3.8 \pm 1.4$ & 0.514 \\
Total average abundance & $0.15 \pm 0.44$ & $4.27 \pm 5.53$ & $5.25 \pm 7.03$ & $8.9 \pm 7.9$ & 0.324 \\
$\begin{array}{l}\text { Brillouin index } \\
\text { (average value) }\end{array}$ & $0.61 \pm 0.26$ & $0.61 \pm 0.36$ & $0.41 \pm 0.36$ & $0.72 \pm 0.29$ & 0.059
\end{tabular}

Dominant species Hysterothylacium sp. Hysterothylacium sp. Hysterothylacium sp. Hysterothylacium sp.

\begin{tabular}{lllllll} 
Berger-Parker Index & $0.67 \pm 0.16$ & $0.70 \pm 0.20$ & $0.76 \pm 0.18$ & $0.63 \pm 0.17$ & $4.85^{*}$ & Sum-Aut \\
\hline
\end{tabular}

${ }^{*}$ significant values

A sequential sum of squares (Type I SS) was applied because host size was introduced as a covariable (ANCOVA model) due to the known effect of fish size-age on parasite burdens. The structures of parasite infracommunities between the samples per seasons (1 infracommunity composition between were tested using the same samples in a similar way for dry season and rainy season using a $1 \times 2$ factorial design with tropical climate as the random factor. $\times 4$ factorial design, with seasonal as the random factor) by testing for the main effects after 9,999 permutations. The differences in

The same model was tested for differences in dispersion using the PERMDISP routine (Anderson et al., 2008). Dispersion distances to centroids were measured and each term in the analysis was

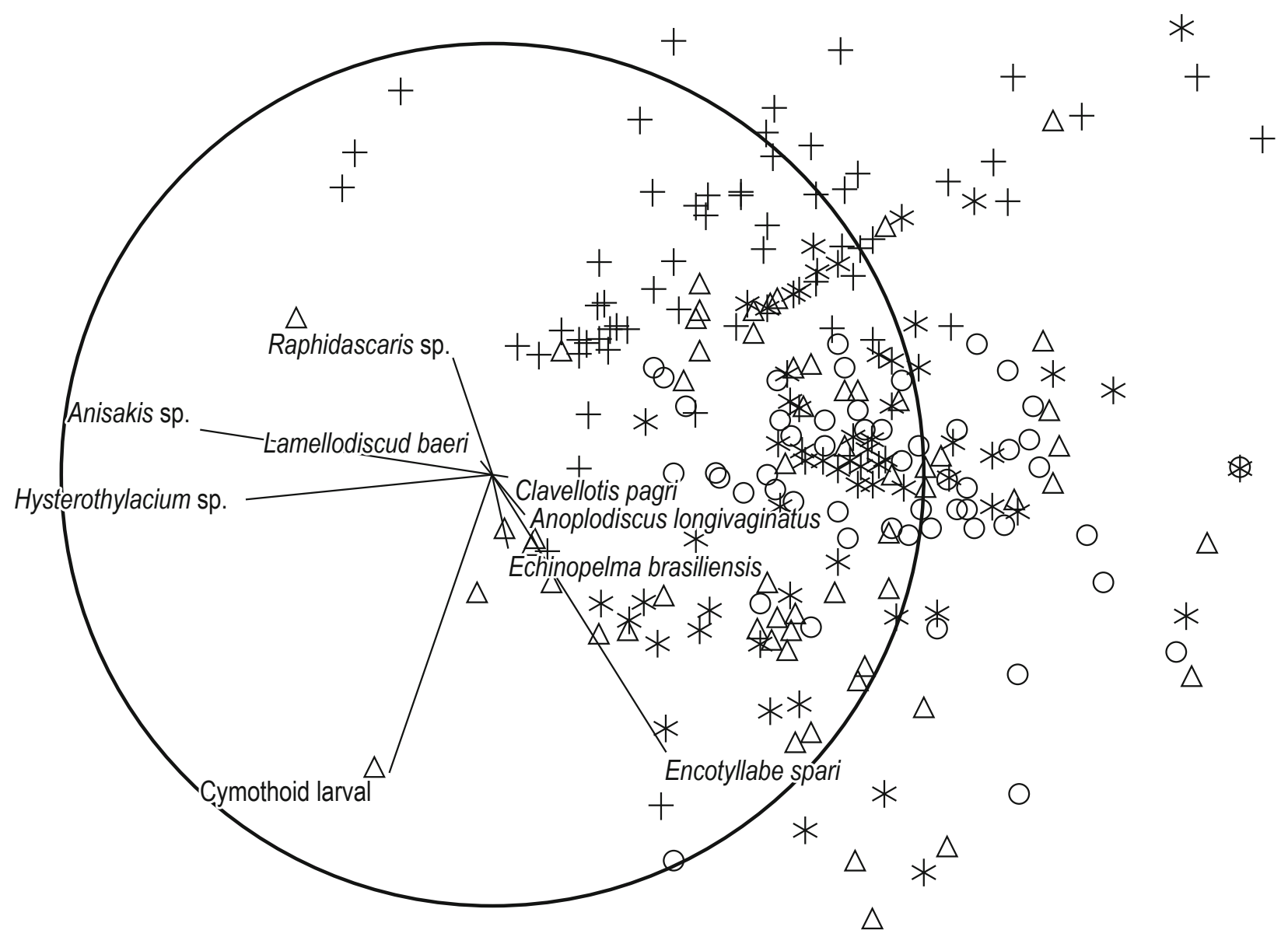

Fig. 1. Non-metric multidimensional scaling (NMDS) graph on the axes of a two-dimensional solution of tri-dimensional 240 infracommunity helminth based on Bray-Curtis similarities of transformed data log $(x+1)$ abundance of parasitic (stress $=015)$. Vectors are Spearman correlations of helminth species abundances with NMDS axes. (The circle represents a correlation of 1). Symbols should be interpreted as follows: + summer; $\Delta$ Autumn; ${ }^{*}$ winter; $\circ$ spring 
tested using 9,999 permutations, with significant terms investigated using a posteriori pairwise comparisons with the PERMANOVA t-statistic (Anderson et al., 2008). Statistical analyses were carried out using the PRIMER® v. 6 and PERMANOVA +for PRIMER software (Clarke \& Gorley, 2006; Anderson et al., 2008).

\section{Results}

All specimens of Pagrus pagrus examined were infected with at least one parasite species. A total of 11,117 metazoan parasites (helminths and crustaceans) of 21 species were collected ( 2 adult digeneans, 6 monogeneans, 1 larval acanthocephalan, 6 nematodes - 1 adult and 5 larvae, 3 copepods and 2 isopods - see Table 1). The most prevalent and abundant were anisakid larvae that represented as many as $58 \%$ of all parasites. Out of these, larvae of Hysterothylacium sp. were represented by 5.496 specimens $(85 \%)$. Anisakid larvae were present in all samples with peak prevalence of Anisakis sp. and Raphidascaris sp. in summer. Hysterothylacium sp. maintained high prevalence in all seasons. Monogeneans had their maximum prevalence and abundance in autumn and spring. Significant difference was found only for the occurrence of Echinopelma brasiliensis between the summer and autumn (ANOVAF $=4.05 ; P<0.05$ ), whereas no seasonal changes were found in the abundance of remaining species (Table 2). Values of mean parasite richness, mean abundance and Brillouin index did not differ between seasons and the Berger-Parker index showed significant difference between summer and autumn (ANOVA $F=4.85 ; P<0.05$ ) (Table 3).

Figure 1 displays the The NMDS ranking of 240 helminth infracommunities that was based on abundance data that had previously been $[\log (x+1)]$ transformed. The results show a separation observed among spring and summer samples. This pattern was statistically significant (1-way ANOSIM, P < 0.01). Species correlation with the NMDS axes (Fig. 1) indicated that the abundance of nematode larvae of Anisakis sp. and Raphidascaris sp. tended to be positively associated with the summer, whereas monogeneans Encotyllabe spari and Lamellodiscus baeri with autumn. Similar results were found for dry and rainy seasons (Fig. 2).

The results from the PERMANOVA analysis showed that there was no interaction between host length with the seasons (Table 4). However, the seasonal factor levels differed between seasons. PERMDISP was significant comparing the results confirmed seasonal differences between summer/spring, autumn/spring and winter/spring (Table 4). Results were similar for rainy season and

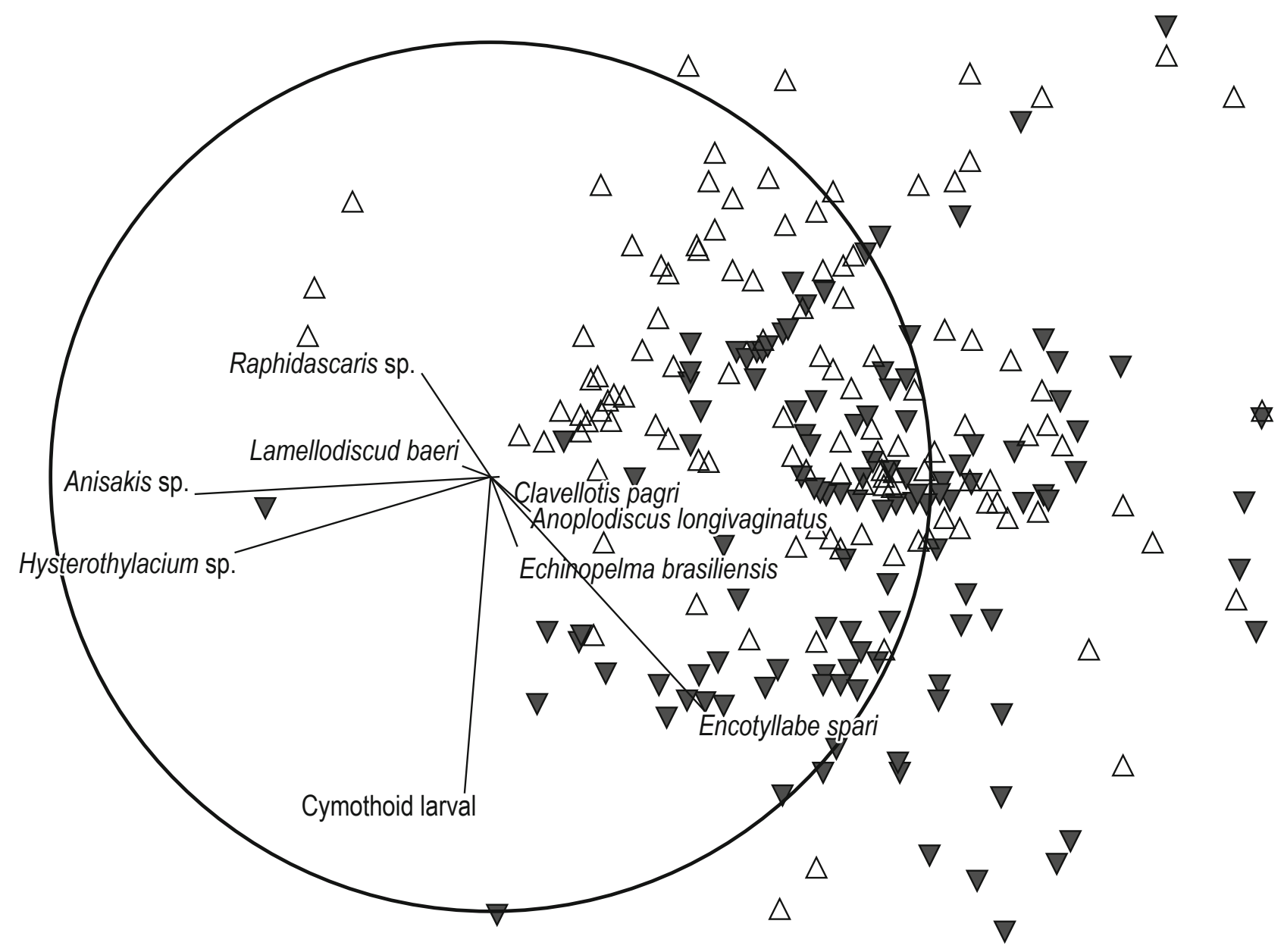

Fig. 2. Non-metric multidimensional scaling (NMDS) chart on the two-dimensional axes of a three-dimensional solution of 240 infracommunity helminth based on BrayCurtis similarity of transformed data log $(x+1)$ of parasite abundance (stress $=015$ ). Vectors are Spearman correlations of helminth species abundances with NMDS axes. (The circle represents a correlation of 1). Symbols should be interpreted as follows: $\nabla$ dry season; $\Delta$ rainy season 
Table 4. Sources of variation in the abundance of seven species of helminths analyzed by permutational multivariate analysis of variance (PERMANOVA) based on Bray-Curtis similarities with transformed abundance data log $(x+1)$. Permutation test for homogeneity of multivariate dispersion (PERMDISP) was applied to test differences in dispersion between groups formed by the factors in which the values were significant for PERMANOVA

\begin{tabular}{|c|c|c|c|c|}
\hline & \multicolumn{2}{|c|}{ PERMANOVA } & \multicolumn{2}{|c|}{ PERMDISP } \\
\hline & Pseudo-F & $P$ & Pseudo- $F$ & $P_{\text {(Disp) }}$ \\
\hline Seasons & 2.8316 & $0.0183^{*}$ & 4.4127 & $0.0268^{*}$ \\
\hline Length & 0.65379 & 0.7825 & & \\
\hline \multirow[t]{3}{*}{ Seasons $x$ Length } & 1. 2004 & 0.2498 & & \\
\hline & \multicolumn{2}{|c|}{ PERMANOVA paired } & \multicolumn{2}{|c|}{ PERMDISP paired } \\
\hline & \multicolumn{2}{|c|}{$P$} & \multicolumn{2}{|c|}{$P$} \\
\hline Summer - Autumn & \multicolumn{2}{|c|}{0.0001} & \multicolumn{2}{|c|}{0.575} \\
\hline Summer - Winter & \multicolumn{2}{|c|}{0.0001} & \multicolumn{2}{|c|}{0.706} \\
\hline Summer - Spring & \multicolumn{2}{|c|}{0.0001} & \multicolumn{2}{|c|}{$2.43 \mathrm{E}-2^{*}$} \\
\hline Autumn - Winter & \multicolumn{2}{|c|}{0.1823} & \multicolumn{2}{|c|}{0.3453} \\
\hline Autumn - Spring & \multicolumn{2}{|c|}{0.0001} & \multicolumn{2}{|c|}{$1.8 \mathrm{E}-3^{*}$} \\
\hline Winter - Spring & \multicolumn{2}{|c|}{0.0001} & \multicolumn{2}{|c|}{$5.4 \mathrm{E}-2^{*}$} \\
\hline
\end{tabular}

dry season without interaction with host length and significant between rainy season (spring and summer) and dry season (autumn and winter) (Table 4).

\section{Discussion}

One of the most important aspects of tropical climate is that the annual seasonality is characterized more by water concentration than thermal variation. Most of the area of Brazil is located in the inter-tropical zone. Throughout immense area of the Brazilian territory, there is a clear alternation between dry and rainy season. The austral summer occurs between October and March, a period of more abundant rainfall and higher temperatures (Sant'anna, Neto 2005).

The present study detected seasonal patterns in the occurrence of two species of metazoan parasites of Pagrus pagrus with the highest values of prevalence, intensity and abundance of infection. Moreover, there were significant differences in the prevalence and abundance of species collected in two or more seasons. The peaks in parasite prevalence and abundance were mainly in the summer sample for endoparasites and in spring for ectoparasites (rainy season). At the infracommunity level, larvae of anisakid nematodes were dominant in all seasons.

The host length was not determinant in the population parameters of parasites but temporal changes in diet and the biology of the hosts recorded during upwelling and reproduction might influence the degree of infection/infestation of the host, as indicated in the analysis. Total parasite abundance was positively associated with season analysis. In summer, the host population undergoes greater foraging activity in order to store energy for the reproductive period early winter and late summer.

The period of greatest reproductive intensity of $P$. pagrus off the coast of Brazil is between August and December, with spawning season that extends from November to January (Costa et al., 1997). This coincidence between increased nutrient availability and the reproductive period is a strategy used by marine teleosts to ensure that the larvae have access to a greater concentration of food, thereby preventing their spreading out over a wider area and benefitting their survival (Bakun \& Parrish, 1990). The greater foraging activity by $P$. pagrus in summer was reflected in the quantitative and qualitative characteristics of populations of metazoan endoparasites. With the exception of digenean species, a great population aggregation that occurs as a result of reproduction may have led to the greater prevalence and abundance of copepods, represented by Clavellotis pagri, throughout the collection period, with peaks during the reproductive period of the fish.

Among the monogeneans, peak prevalence and abundance occurred in autumn and spring, following the end of the peak breeding period of the fish. A number of authors have reported an association between reproduction and an increase in the prevalence and abundance of species of parasites and have attributed this fact to the physiological stress of the host during the breeding period, as a higher investment in reproduction may decrease the energy allocated to the immune system and thereby facilitate parasite infections (Sheldon \& Verhulst, 1996; White et al., 1996; Lizama et al., 2006).

Anisakid larvae were found in all samples of the year. The feeding plasticity of $P$. pagrus and its intermediate position in the marine food chain indicate its importance as an intermediate or paratenic host for helminth parasites. Larval stages of nematodes were 
found using $P$. pagrus to reach the definitive hosts (Tavares \& Luque, 2006). The intermediate hosts used by anisakid are mainly represented by crustaceans, mollusks and fish, which are the predominant items in the diet of $P$. pagrus (Anderson, 2000). Thus, temporal variations in the availability of food items may have repercussions on the parasite fauna of $P$. pagrus, whereas the abundance and prevalence of parasites with complex life cycles depends directly on the free-living fauna (Campbell et al., 1980; Campbell, 1983).

Similar results about seasonality was reported by Carvalho and Luque (2011), composition and structure of parasite communities of Trichiurus lepturus as consequence of environmental changes and upwelling, as well as behavioral and physiological changes in host (increase in feeding and reproduction) led to immediate changes.

In rainy season (spring, summer), concentrates the upwelling phenomena, breeding and spawning of $P$. pagrus possible responsibles for differences at parasite community in these periods. Suggesting that the sasonal variation in the parasites community was influenced for these phenomena.

\section{References}

Anderson, M.J., Gorley, R.N. Clarke, K.R. (2008): PERMANOVA for PRIMER: Guide to statistical methods. PRIMER-E, Plymouth; U.K. 240 pp.

Anderson, R.C. (2000): Nematode Parasites of Vertebrates: Their development and transmission. $2^{\text {nd }}$ Edition, Walingford, UK, CABI Publishing, $650 \mathrm{pp}$.

Ávila-Da-Silva, A.O., HaImovicl, H. (2004): Diversidade e associação de espécies nas capturas de espinhel-de-fundo. In: Halmovicl H., Ávila-da-Silva A.O., Rossi-Wongtschowski, L.D.B. (Eds) Prospecção Pesqueira de Espécies Demersais com Espinhel-de-fundo na Zona Econômica Exclusiva da Região Sudeste-Sul do Brasil. Série Documentos Revizee - Score Sul, Instituto Oceanográfico - USP, São Paulo: 93 - 110.

Bakun, A., PARRISH, R.H. (1990): Comparative studies of coastal pelagic fish reproductive habitats: the Brazilian sardine (Sardinella aurita). J. Cons. int. Explor. Mer., 46: 269 - 283. DOI: 10.1093/ icesjms/46.3.269

Barber, I., Poulin, R. (2002): Interactions between fish, parasites and disease. In: Hart, P.J.B., ReYnolds, J.D. (Eds) Handbook of Fish Biology and Fisheries. Oxford: Blackwell Publishing, 359 389

BRAGA, A.C. (2001): 0 ambiente e a biodiversidade. In: BizerRIL, C.R.S.F.; Costa, P.A.S. (Eds), Peixes Marinhos do Estado do Rio de Janeiro, Rio de Janeiro: Fundação de Estudos do Mar, 13-32. BRANDINI, F.P. (1990): Producão primária e características fotossintéticas do fitoplâncton na Região Sudeste do Brasil. Braz. J. Oceanogr., 38: 147 - 159

Bush, A.O., Aho, J.M., Kennedy, C.R. (1990): Ecological versus phylogenetic determinants of helminth parasite community richness. Evol. Ecol., 4: 1 - 20. DOI: 10.1007/BF02270711

Campbell, R. (1983): Parasitism in the deep sea. In: Rowe, G.T. The Sea. New Jersey: Wiley and Sons Inc., $473-552$

Campbell, R., Haedrich, R.L., MunRoe, T.A. (1980): Parasitism and ecological relationships among deep-sea benthic fishes. Mar. Biol., 57: 301 - 313. DOI: 10.1007/BF00387573

Carvalho, A.R., Luque, J.L. (2011): Seasonal variation in parasites of Trichiurus lepturus (Perciformes: Trichiuridae) of Rio de Janeiro, Brazil. Braz. J. Biol., 71: 771 - 782. DOI: 10.1590/S151969842011000400024

ClARKE, K.R. (1993): Non-parametric multivariate analyses of changes in community structure. Aust. J. Ecol., 18, 117 - 143. DOI: 10.1111/j.1442-9993.1993.tb00438.x

Clarke, K.R., Gorley, R.N. (2006): PRIMER v6: User manual/ tutorial. PRIMER-E Ltd., Plymouth U.K., 190 pp.

ClaRKE, K.R., WarWICK, R.M. (2001): Change in marine communities: an approach to statistical analysis and interpretation. Plymouth, PRIMER-E. UK, $2^{\text {nd }}$ ed., $172 \mathrm{pp}$.

Cohen, S.C., Justo, M.C.N., Kohn, A. (2013): South American Monogenoidea Parasites of Fishes, amphibians and reptiles. Rio de Janeiro: Ed. Oficina de Livros, p .663

Costa, P.A.S., Fagundes-Netto, E.B., Gaelzer, L.R., Lacerda, P.S., Monteiro-Ribas, W.M. (1997): Crescimento e ciclo reprodutivo do pargo-rosa (Pagrus pagrus Linnaeus, 1758) na Região do Cabo Frio, Rio de Janeiro. Nerítica 11: 139 - 154

Díaz, F., George-Nascimento, M. (2002). Estabilidad temporal de las infracomunidades de parasitos em la borrachilla Scartichthys viridis (Valenciennes, 1836) (Pisces: Blenniidae) em la costa central de Chile. Rev. Chil. Hist. Nat., 75, 4: 641 - 649. DOI: 10.4067/ S0716-078X2002000400001

Eiras, J.C., Pavanelli, G.C., Takemoto, R.M.(2006): Métodos de estudo e técnicas laboratoriais em parasitologia de peixes. 2 ed. Maringá: EDUEM,. 199 p.

GARNick, E., MARGolis, L. (1990): Influence of four species of helminth parasites on orientation of seaward migrating sockeye salmon (Onchorhynchus nerka) smolts. Can. J. Fish Aquat. Sci., 47: 2380 - 2389. DOI: 10.1139/f90-265

Gordon, D.M., Rau, M.E. (1982): Possible evidence for mortality induced by the parasite Apatemon gracilis in a population of brook sticklebacks (Culaea inconstans). Parasitology, 84: 41 - 47. DOI: 10.1017/S0031182000051647

Hassel, L., Venturotti, A., Magalhaes, F., Cuenca, S., Siciliano, S., MARQUES, F.C. (2003): Summer sightings of dwarf minke whales (Balaenoptera acutorostrata) off the eastern coast of Rio de Janeiro State, Brazil. Lat. Am. J. Aquat. Mamm., 2: 47 - 50. DOI: 10.5597/lajam00030

Kohn, A., Fernandes, B.M.M., Cohen, S.C. (2007): South American Trematodes Parasites of Fishes. Rio de Janeiro. 318 p.

Lizama, M.A.P., TAKemoto, R.M., PAVAnelli, G.C. (2006): Influence of the seasonal and environmental patterns and host reproduction on the metazoan parasites of Prochilodus lineatus. Braz. Arch. Biol. Technol., 49: 611 -622. DOI: 10.1590/S1516-89132006000500011 LUQUE, J.L. (2004): Biologia, epidemiologia e controle de parasitos de peixes. Rev. Bras. Parasitol. Vet., 13: 161 - 164

Luque, J.L., Vieira, F.M., Takemoto, R. M., Pavanelli, G.C., Eiras, J.C. (2013): Checklist of Crustacea parasitizing fishes from Brazil. Check List, 9: 1449 - 1470.

Manooch, C.S. III., HASSLER, W.M. (1978): Synopsis of biological data on the red porgy, Pagrus pagrus (Linnaeus). FAO Fish. Synop., 116: 1 - 19 
Menezes, N.A., Figueiredo, J.L. (1980): Manual de Peixes Marinhos do Sudeste do Brasil. IV. Teleostei (3). São Paulo: Museu de Zoologia, Universidade de São Paulo, 90 pp.

Palacio, F.J. (1982): Revisión and zoogeográfica marina del Sur del Brasil. Bol. Inst. Oceanogr., 31: 69 - 72

Poulin, R., Fitzgerald, G.J. (1987): The potential of parasitism in the structuring of a salt marsh stickleback community. Can. J. Zool., 65: 2793 - 2798. DOI: 10.1139/z87-421

Poulin, R., Valtonen, E.T. (2002): The predictability of helminth community structure in space: a comparison of fish populations from adjacent lakes. Int. J. Parasitol., 32: 1235 - 1243. DOI:10.1016/S0020-7519(02)00109-1

Sant'Anna-Neto, J.L. (2005): Decálogo da climatologia do Sudeste brasileiro. Rev. Bras. Climatol., 1: 43 - 60

Santos, C.P., Gibson, D.I., TAvares, L.E.R and Luque, J.L.(2008): Checklist of Acanthocephala associated with the fishes of Brazil. Zootaxa, 1938, p.1 - 22

Sheldon, B.C., VeRHULST, S. (1996): Ecological immunology: costly parasite defences and trade-offs in evolutionary ecology. Trends Ecol. Evol., 11: 317 - 321. DOI: 10.1016/0169-5347(96)10039-2
Soares I.A.,Vieira, F.M., Luque, J.L.(2014): Parasite community of Pagrus pagrus (Sparidae) from Rio de Janeiro, Brazil: evidence of temporal stability. Braz. J. Vet. Parasitol., 23: 216 - 223. DOI: 10.1590/S1984-29612014047

Tavares, L.E.R., Luque, J.L. (2006):. Sistemática, biologia e importância em saúde coletiva de larvas de Anisakidae (Nematoda: Ascaridoidea) parasitas de peixes ósseos marinhos do Estado do Rio de Janeiro, Brasil. In: SIlvA-SouzA, A.T. (Ed). Sanidade de Organismos Aquáticos no Brasil. Maringá: Abrapoa. 297 - 328

Valentin, J.L., Monteiro-Ribas, W.M. (1993): Zooplankton community structure on the east southeast Brazilian continental shelf (18-23오 latitude). Cont. Shelf. Res., 13: 407 - 424. DOI: 10.1016/0278-4343(93)90058-6

White, K.A.J., Grenfel, B.T., Hendry, R.J., Lejeune, O., Murray, J.D. (1996): Effect of seasonal host reproduction on host-macroparasite dynamics. Math. Biosci., 137: 79 - 99. DOI: 10.1016/ S0025-5564(96)00061-2

ZAR, J.H. (1996): Biostatistical Analysis, 3rd edn. New Jersey: Prentice Hall Inc. 